\title{
PENGENALAN TEKNOLOGI VIRTUAL REALITY DAN AUGMENTED REALITY SEBAGAI PENDUKUNG EDUKASI UNTUK SEKOLAH MENENGAH DI GRESIK
}

\author{
Sritrusta Sukaridhoto \\ Politeknik Elektronika Negeri Surabaya, dhoto@pens.ac.id \\ Hestiasari Rante \\ Politeknik Elektronika Negeri Surabaya, hestiasari@pens.ac.id \\ Muhammad Agus Zainuddin \\ Politeknik Elektronika Negeri Surabaya, magusz@pens.ac.id \\ Rizqi Putri Nourma Budiarti \\ Universitas Nahdlatul Ulama Surabaya, rizqi.putri.nb@unusa.ac.id
}

\begin{abstract}
Abstrak
Dunia telah memasuki zaman Industry 4.0, dimana teknologi pendukungnya adalah Virtual Reality (VR) dan Augmented Reality (AR). Saat ini teknologi VR/AR sudah semakin berkembang pesat, sudah banyak peneliti dan industri yang mengembangkan aplikasi VR/AR. VR adalah teknologi komputer yang mampu memreplikasi lingkungan real maupun hayal dan mampu menstimulasi kondisi fisik pengguna sehingga mampu berinteraksi. Perangkat yang digunakan untuk dapat menggunakan teknologi VR ada berbagai macam, dari perangkat Head-MountedDisplay, perangkat masukan, perangkat lunak, konten, hingga perangkat gabungan. Pengetahuan tentang teknologi VR ini bias didapat dari Internet. Namun apakah teknologi ini sudah dikenal oleh masyarakat Indonesia, khususnya sekolah sebagai pendukung kegiatan edukasi? terutamanya oleh siswa menengah dalam membantu siswa untuk belajar dan mencari pengetahuan. Untuk menjawab permasalahan tersebut, Kami mengadakan kegiatan pengabdian masyarakat dengan judul "Pengenalan Teknologi Virtual Reality dan Augmented Reality sebagai Pendukung Edukasi untuk Siswa Menengah di Gresik". Dimana dalam kegiatan tersebut Kami menjelaskan cara kerja teknologi VR/AR, implementasi penggunaan teknologi VR/AR berserta contoh-contoh aplikasi yang dapat digunakan untuk edukasi, dan penjelasan tentang aplikasi VR/AR yang tidak baik untuk siswa. Dari hasil pengamatan didapatkan bahwa $80 \%$ penggunaan teknologi VR/AR mudah dan berguna untuk edukasi, namun untuk implementasinya masih membutuhkan biaya.
\end{abstract}

Kata Kunci: virtual reality, augmented reality, edukasi.

\section{Abstract}

The world has entered the era of Industry 4.0, where the supporting technology is Virtual Reality (VR) and Augmented Reality (AR). Nowadays the VR / AR technology has increasingly developed rapidly, many researchers and industries have developed VR / AR applications. VR is a computer technology that is capable of replicating the real and biological environment and is able to stimulate the user's physical condition so that they can interact. There are various kinds of devices used to be able to use VR technology, from Head-Mounted-Display devices, input devices, software, content, to combined devices. Knowledge of this VR technology 
can be obtained from the Internet. But is this technology already known by the people of Indonesia, especially schools as supporting education activities? especially by junior high school students in helping students to learn and seek knowledge. To answer this problem, we held a community service activity titled " Pengenalan Teknologi Virtual Reality dan Augmented Reality sebagai Pendukung Edukasi untuk Siswa Menengah di Gresik". Where in the activity we explain how the VR / AR technology works, the implementation of the use of VR / AR technology along with examples of applications that can be used for education, and an explanation of VR / AR applications that are not good for students. From the observations it was found that $80 \%$ use of VR / AR technology is easy and useful for education, but for its implementation it still requires money.

Keywords: virtual reality, augmented reality, education.

\section{PENDAHULUAN}

Saat ini teknologi Virtual Reality (VR) sudah semakin berkembang pesat, sudah banyak peneliti dan industri yang mengembangkan aplikasi VR. VR adalah teknologi komputer yang mampu memreplikasi lingkungan real maupun hayal dan mampu menstimulasi kondisi fisik pengguna sehingga mampu berinteraksi. Perangkat yang digunakan untuk dapat menggunakan teknologi VR ada berbagai macam, dari perangkat HeadMounted-Display, perangkat masukan, perangkat lunak, konten, hingga perangkat gabungan. Pengetahuan tentang teknologi VR ini bisa didapat dari Internet.

Tak dapat dipungkiri memang teknologi VR dapat membantu untuk mensimulasikan suatu kondisi, sehingga pengguna mampu belajar dari simulasi dengan menggunakan VR. Teknologi
VR semakin memberikan dampak yang besar untuk masyarakat, tidak terkecualinya di bidang edukasi. Manfaat lainnya dari teknologi VR adalah efisiensi dan penghematan material, karena dengan menggunakan VR kita tidak perlu takut lagi apabila kita tidak memiliki atau kehabisan material atau bahan. Sebagai contoh: untuk kegiatan praktikum kimia, dimana diperlukan material atau bahan kimia dengan jumlah yang banyak untuk semua siswa. Namun dengan menggunakan VR, sekolah tidak perlu khawatir dengan jumlah yang diperlukan. Riset group Human Centric Multimedia telah berhasil membuat sebuah aplikasi VR dengan tema praktikum Kimia dengan memanfaatkan Oculus Rift yang digabungkan dengan Leap-Motion sehingga pengguna mampu berinteraksi seperti sedang melakukan praktikum 
tetrasi kimia. Selain itu juga ada aplikasi VR-Lab dan VR-Athletic.

Namun apakah teknologi ini sudah dikenal oleh masyarakat Indonesia, khususnya sekolah yang mampu menggunakan teknologi ini sebagai pendukung kegiatan edukasi? Khususnya oleh siswa menengah dalam hal untuk membantu siswa belajar dan mencari pengetahuan.

Untuk menjawab permasalahan tersebut, Kami melaksanakan kegiatan pengabdian masyarakat dengan judul "Pengenalan Teknologi Virtual Reality dan Augmented Reality sebagai Pendukung Edukasi untuk Siswa Menengah di Gresik”. Kegiatan yang dilakukan adalah dengan melakukan seminar sehari. Dimana dalam kegiatan tersebut Kami menjelaskan cara kerja teknologi VR/AR, implementasi penggunaan teknologi VR/AR berserta contoh-contoh aplikasi yang mendukung edukasi, dan penjelasan tentang aplikasi VR/AR yang tidak baik untuk siswa.

GAMBARAN

UMUM

\section{MASYARAKAT SASARAN}

Sekolah Menengah Pertama Negeri

3 Gresik adalah sekolah menengah yang sudah bertaraf Internasional. Sekolah tersebut juga sudah memiliki koneksi Internet yang digunakan oleh Guru dan Siswa. Namun pada sekolah tersebut teknologi VR/AR belum pernah digunakan untuk mendukung kegiatan edukasi belajar mengajar.

SMPN 3 Gresik beralamatkan Jl. Panglima Sudirman 100 Sidokumpul, Kec. Gresik, Kab. Gresik Prov. Jawa Timur. Jarak tempuh dari instansi peneliti menuju ke lokasi berkisar 27 Km. Dimana sekolah ini memiliki 51 jumlah guru, 858 siswa, 27 rombongan belajar, menggunakan kurikulum K-13, memiliki fasilitas 24 ruang kelas, 2 laboratorium, dan 1 perpustakaan.

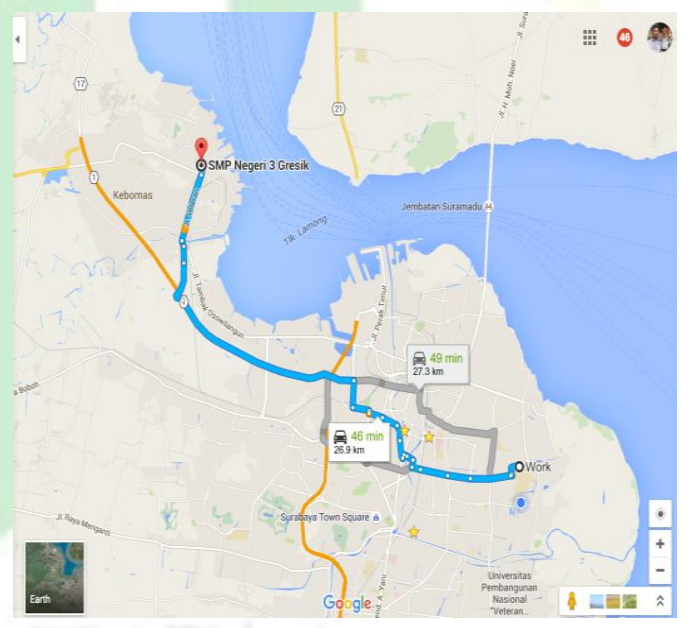

Gambar 1. Peta lokasi.

\section{METODE}

Pengabdian masyarakat ini menggunakan metode Design Thinking. Dimana langkah-langkah yang dilakukan memiliki 5 tahap yaitu (1) Empati, (2) Definisi, (3) Ideasi, (4) Prototype, dan (5) Test. 
Pada proses Empati, kami melakukan analisa dan pemahaman mengenai permasalahan yang berhubungan dengan tema penggunaan teknologi VR/AR di sekolah. Dimana kami melakukan survey dan tanya jawab secara langsung dengan target pengguna. Dari proses empati ini didapatkan bahwa sudah banyak guru dan siswa yang mendengar tentang teknologi VR/AR, namun mereka belum pernah menggunakan baik untuk hiburan bahkan yang berhubungan dengan edukasi.

Dilanjutkan dengan proses Definisi, pada proses ini kami melakukan breakdown dan list permasalahan yang terjadi dari hasil survey. Dari hasil survey kami mendapatkan data bahwa SMPN 3 Gresik belum mengetahui perangkat dan teknologi pendukung dari VR/AR.

Sehingga dari breakdown permasalahan tersebut kami membuat ide pada proses Ideasi berupa seminar sehari dengan mempersiapkan perangkat keras, perangkat lunak dan juga daftar konten VR/AR yang berhubungan dengan edukasi.

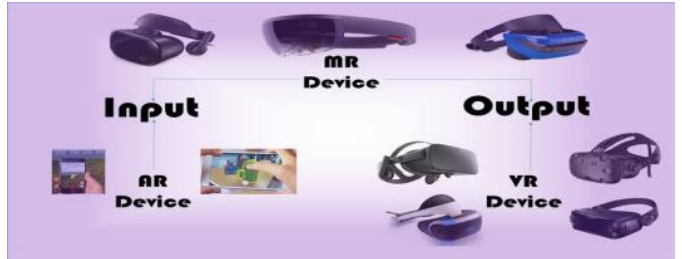

Gambar 2. Perangkat VR/AR.

Pada proses prototipe, kami mempersiapkan perangkat VR/AR dari yang low-end hingga high-end. Dimana perangkat low-end untuk VR/AR adalah menggunakan smartphone yang dilengkapi dengan Cardboard, meningkat ke perangkat VR/AR yang menggunakan GearVR dengan smartphone dan controller khusus, hingga perangkat VR high-end Oculus Riff yang terhubung dengan PC dan Oculus Quest perangkat VR standalone. Selain perangkat keras kami menyiapkan aplikas-aplikasi yang berhubungan dengan edukasi dimana list dapat dilihat pada Tabel 1.

Tabel 1. List aplikasi VR/AR untuk Edukasi.

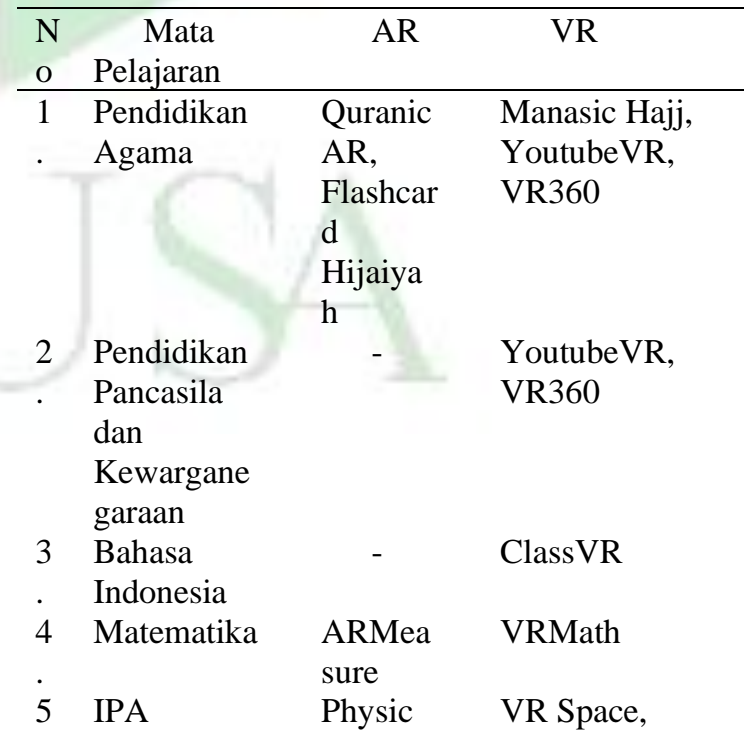




\begin{tabular}{|c|c|c|c|}
\hline . & & $\begin{array}{l}\text { Lab, } \\
\text { AR } \\
\text { Molecul } \\
\text { e }\end{array}$ & $\begin{array}{l}\text { Unimersiv, } \\
\text { VR Molecule, } \\
\text { Chemistry VR }\end{array}$ \\
\hline 6 & IPS & EduApp & $\begin{array}{l}\text { Unimersiv } \\
\text { VR }\end{array}$ \\
\hline 7 & $\begin{array}{l}\text { Bahasa } \\
\text { Inggris }\end{array}$ & EduApp & $\begin{array}{l}\text { ClassVR, VR } \\
\text { Orator }\end{array}$ \\
\hline 8 & $\begin{array}{l}\text { Seni } \\
\text { Budaya }\end{array}$ & - & $\begin{array}{l}\text { YoutubeVR, } \\
\text { Class VR }\end{array}$ \\
\hline 9 & $\begin{array}{l}\text { Pendidikan } \\
\text { Jasmani }\end{array}$ & - & $\begin{array}{l}\text { Sport } \\
\text { Scramble }\end{array}$ \\
\hline $\begin{array}{l}1 \\
0\end{array}$ & Prakarya & EduApp & $\begin{array}{l}\text { Tilt Brush, } \\
\text { Gravity } \\
\text { Sketch }\end{array}$ \\
\hline
\end{tabular}

Test. Dimana kami menyiapkan acara seminar dengan lokasi di SMPN 3 Gresik dengan audiensi para Guru. Kami menyiapkan perangkat tersebut di lokasi dan menyiapkan demonstrasi untuk pengunaan seluruh perangkat keras dan perangkat lunak. Selain itu kami menyiapkan kuisioner dengan pertanyaan yang berhubungan dengan VR/AR. List pertanyaan dan pilihan jawaban:

1. Bagaimana tingkat kesulitan Teknologi VR/AR untuk Edukasi?
a. Sukar
b. Sedang
c. Mudah

2. Bagaimana menurut anda manfaat teknologi VR/AR Edukasi?
a. Kurang
b. Cukup
c. Bermanfaat

3. Apakah teknologi VR/AR Edukasi mudah untuk dipelajari?
a. Sukar
b. Sedang
c. Mudah

4. Bagaimana tingkat kesulitan dalam menggunakan tekonologi VR/AR untuk edukasi?
a. Sukar
b. Sedang
c. Mudah

5. Bagaimana segi ekonomis teknologi VR/AR Edukasi?
a. Mahal
b. Sedang
c. Murah

6. Apakah teknologi VR/AR Edukasi dapat meningkatkan kinerja anda dalam mendidik?
a. Kurang
b. Cukup
c. Bermanfaat

\section{HASIL DAN PEMBAHASAN}

Hasil luaran dari kegiatan pengabdian masyarakat ini adalah seminar sehari. Beberapa foto kegiatan dapat dilihat di Gambar 3 hingga Gambar 8.

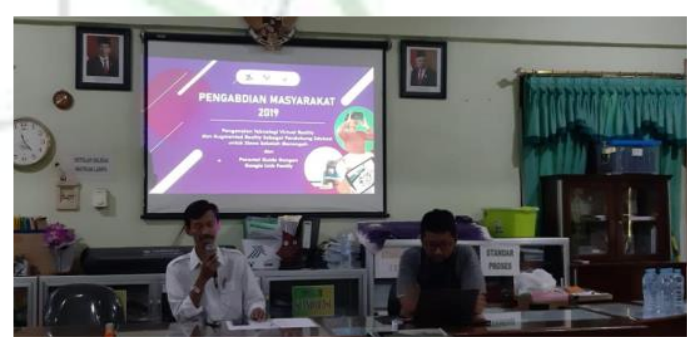

Gambar 3. Posisi pemateri di ruang seminar. 


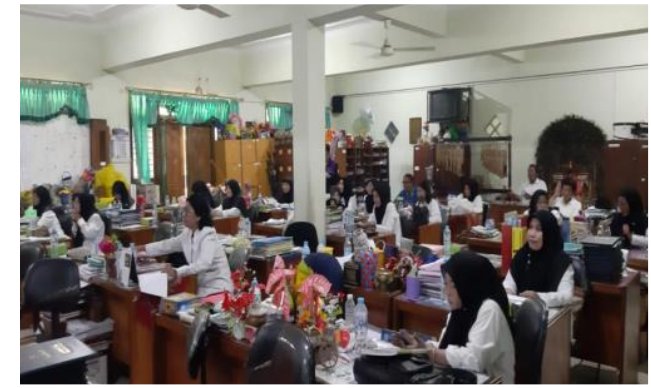

Gambar 4. Peserta.

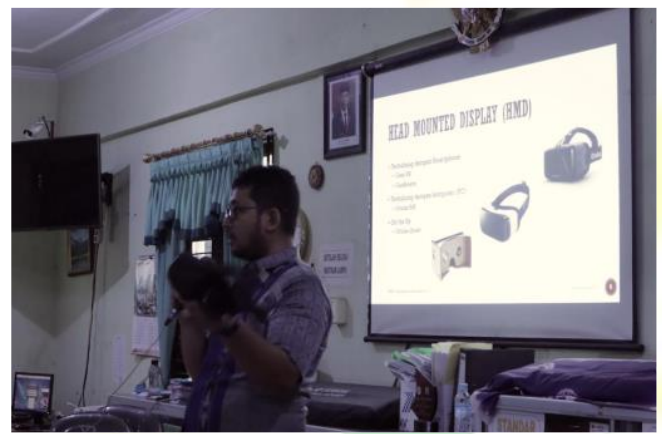

Gambar 5. Penyajian materi dengan

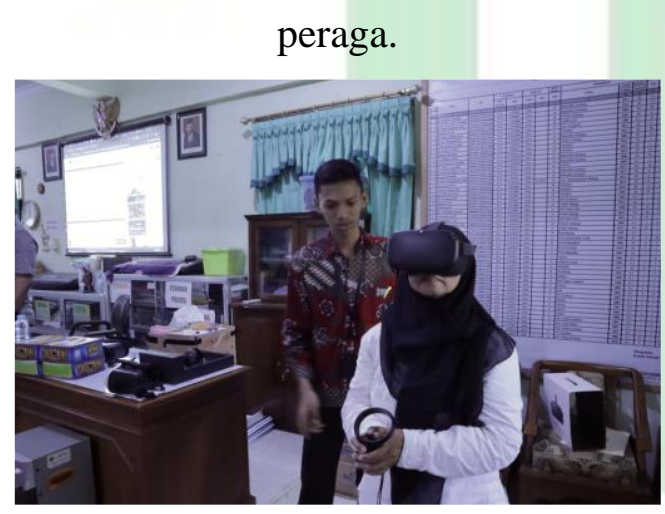

Gambar 6. Peserta mencoba langsung.

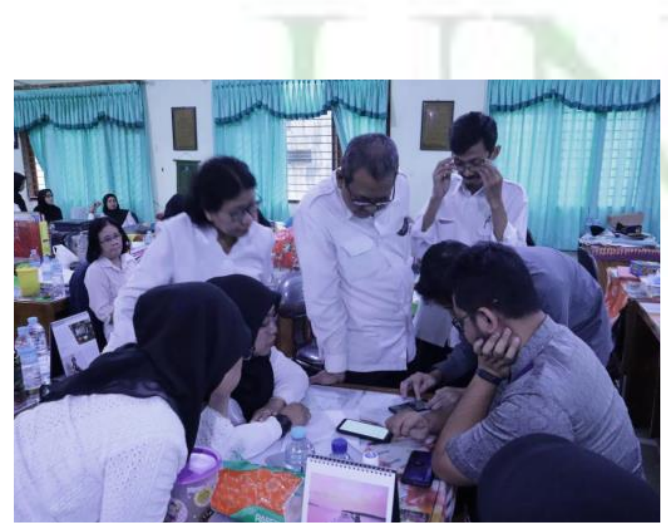

Gambar 7. Percobaan aplikasi.

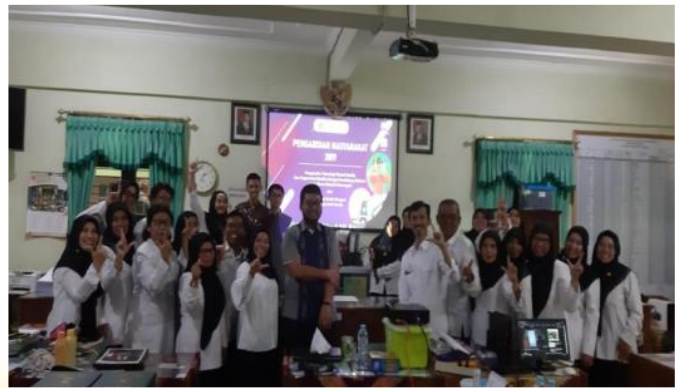

Gambar 8. Akhir kegiatan.

Selain itu diberikan kuisioner kepada 43 peserta yaitu para Bapak Ibu Guru SMPN 3 Gresik, dengan komposisi umur antara 28 tahun hingga 58 tahun. Dengan jumlah Guru laki-laki 32 orang dan wanita adalah 11 orang. Hasil dari kuisioner dapat dilihat pada

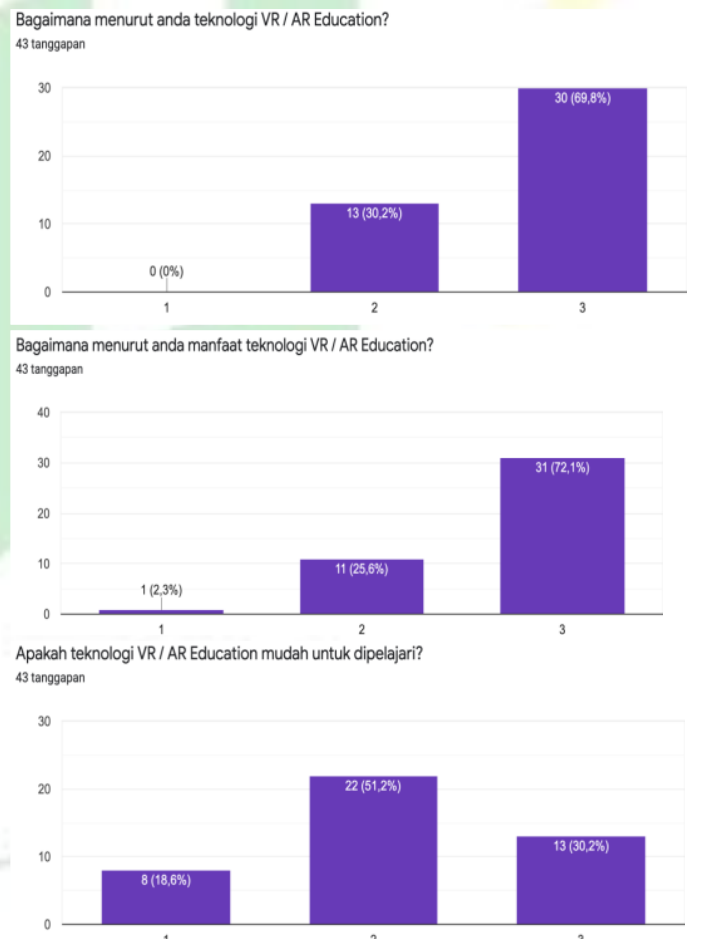




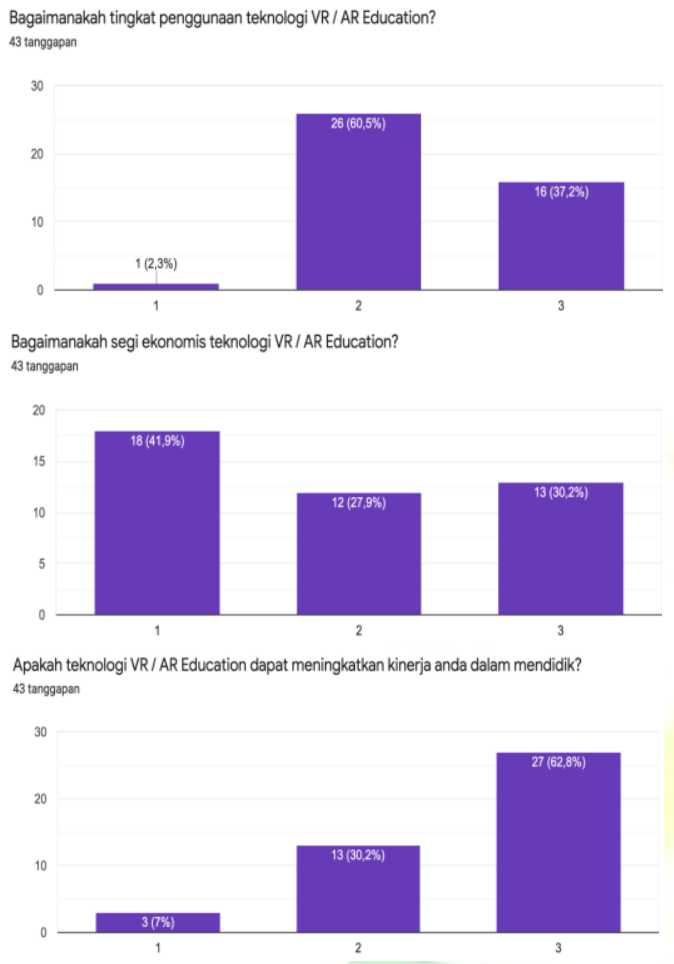

Gambar 9. Hasil kuisioner.

Dari hasil kuisioner dapat dianalisa bahwa $51 \%$ lebih menyatakan teknologi VR/AR untuk edukasi cukup mudah untuk dipelajari dan diimplementasikan, dengan hasil kuisioner lebih dari $62 \%$ selain itu juga teknologi ini sangat bermanfaat untuk bidang Pendidikan. Namun dengan hasil kuisiner $41 \%$ menyatakan teknologi ini masih mahal dan $27,9 \%$ masih menyatakan tidak murah.

\section{KESIMPULAN}

Kegiatan pengabdian masyarakat dengan tujuan mengenalkan teknologi VR/AR kepada SMPN 3 Gresik dapat disimpulkan bahwa dunia pendidikan di Indonesia siap mengimplementasikan teknologi VR/AR ini, dengan bukti lebih dari $50 \%$ menyatakan cukup mudah mempelajari dan melakukan implementasi. Namun teknologi ini masih terbilang mahal dalam segi ekonomisnya.

\section{REFERENSI}

S. Sukaridhoto, J. Mahmud Hasbulloh, P. Nugroho, L. Hakim, "A Design of 3D Virtual Reality Chemical Lab with Hand Gesture Interaction for Education", in The 5th Annual Basic Science International Conference 2015, pp. 139.

S. Sukaridhoto, Tarmizi Erfandi, Muhammad Fuji Cahyo Kurniawan, Luthfi Hidayat, Sumartini, "Evaluating Virtual Reality Technology for Indonesian Junior High School Education: A Survey" ESL Bandung Indonesia, 2016.

Choiri, M.M., Basuki, A., Bagus, A.Y., Sukaridhoto, S. and Jannah, M., 2017, September. Design and development virtual reality athletic-Virtual imagery to train sprinter's concentration. In 2017 International Electronics Symposium on Knowledge Creation and Intelligent Computing (IES-KCIC) (pp. 161-166). IEEE.

Rengganis, Y. A., M. Safrodin, and S. Sukaridhoto. "Integration Head Mounted Display Device and Hand Motion Gesture Device for Virtual Reality Laboratory." IOP Conference Series: Materials Science and Engineering. Vol. 288. No. 1. IOP Publishing, 2018.

Sumartini, Sritrusta Sukaridhoto, "An Interactive EBook of Civic Education for Indonesian Junior High School", ESL Bali Indonesia, 2014. 